\title{
Posicionamentos da Magistratura brasileira sobre a nova lex mercatoria
}

\author{
Ben-Hur Rava* \\ Luciano da Ros**
}

\section{INTRODUÇÃO}

O objetivo do presente artigo é promover um estudo sobre a postura adotada pelo Poder Judiciário brasileiro quando este decide sobre questões relacionadas à internacionalização da economia nacional, mormente ao que se tem convencionado chamar de nova lex mercatoria.' A reflexão que pauta este estudo é, portanto, diversa das considerações comumente direcionadas às decisões judiciais. O esforço ora empreendido é de traços marcadamente interdisciplinares e valoriza o viés ana- lítico, em prejuízo daquele dito normativo ou prescritivo. O tema, assim, relaciona-se tanto com as incursões do direito na economia e na política, quanto com o debate sobre a judicialização da política e das relações econômicas no Brasil contemporâneo. Busca-se evidenciar, assim, que alguns tipos contratuais muito específicos, recentemente introduzidos nas práticas econômicas, por estarem identificados com o fenômeno da lex mercatoria e da própria globalização da economia, além de possibilitarem uma maior dinamização nas trocas mercantis, também ocasionam

\footnotetext{
" Professor na Faculdade de Direito São Judas Tadeu, advogado, mestre em Direito pela UNISINOS, doutorando em Ciência Política pela UFRGS.

"* Bacharel em Direito. Mestre em Ciência Política pela UFRGS.

1 Trata-se e um conceito histórico que sofreu lenta e gradual evolução no campo do direito comercial. Para se ter um apanhado geral, mas não menos profundo, consulte-se: STRENGER, Irineu. Direito internacional privado. 4. ed. São Paulo: LTr, 2000, p. 745-804. São preciosas as contribuições teóricas dadas ao tema por: GOLDMAN, Berthold. Frontières du droit et lex mercatoria. Archives de Philosophie du Droit, n. 9, p. 177, 1964.
} 
uma nova forma de compreensão do fenômeno jurídico, pelos operadores do direito, em especial os magistrados.

Seguindo este raciocínio, cumpre observar que não raramente, muitas questões que chegam aos tribunais têm características tão marcantes e próprias, que fogem aos limites estritos da técnica jurídica, revelando características tão econômicas e políticas quanto jurídicas. Os temas se confundem, mas essa porção estranha ao direito é freqüentemente negligenciada e o discurso professado pelos operadores do direito acaba dificultando - e por vezes ocultando - a compreensão das reais dimensões do problema discutido.

O presente trabalho versa sobre aquelas situações nas quais o Direito e seus operadores abandonam um linguajar tido por muitos como hermético, formalista e técnico, trazendo para seu universo argumentos que freqüentemente lhe são estranhos, mais afeitos à política è è economia que à ciência jurídica. ${ }^{2}$

Ora, que o direito e que os tribunais se pronunciem sobre temas políticos, entretanto, não é novidade. Basta ob- servar qualquer sessão de julgamento do Supremo Tribunal Federal, que se verá um sem número de temas estritamente políticos sendo tratados, desde a relação entre os poderes até ações propostas por partidos oposicionistas como um mero ato retórico de denúncia. ${ }^{3}$

O que se propõe aqui, contudo, é algo diferente. Trata-se de ver naqueles casos mais corriqueiros, do dia-a-dia dos tribunais de menor envergadura hierárquica, temas evidentemente políticos, que, contudo, não são assim considerados no cotidiano forense. Os casos adotados para fins de análise são a aceitação por parte de tribunais de jurisdição restritamente nacional de contratos veiculados mundialmente, próprios da nova lex mercatoria. Entre estes, encontram-se os de leasing, factoring, franchising e performance bond e aqueles índices internacionais, como, por exemplo, a taxa LIBOR (London Interbank Offered Rate). ${ }^{4}$

A situação legal com relação a esses institutos, no país, é bastante variada, uma vez que tais modelos encontramse dispersos na legislação, havendo

2 Cumpre informar, de início, que o presente artigo não pretende discutir questões relacionadas à análise do discurso ou à hermenêutica juridica, mas tão-só levantar algumas questões relacionadas à racionalidade material pela qual os magistrados encaram os fenômenos econômicos e sua difusão e repercussão política subjacentes à sua tarefa de dizer o direito.

3 WERNECK VIANNA, Luiz Jorge et al. A judicialização da política e das relações sociais no Brasil. Rio de Janeiro: Revan, 1999, p. 127.

4 Este trabalho não pretende ingressar na análise legal e sistemática de cada uma dessas modalidades contratuais e suas aplicações práticas. Os contratos aqui mencionados servem como "modelos jurídicos" de uma argumentação retórica sobre o conteúdo mais amplo da própria nova lex mercatoria. 
uma sistematização normativa rarefeita ou mal articulada com o conjunto do restante ordenamento jurídico. ${ }^{5}$ No caso do contrato de franchising, sua regulação já se encontra feita em lei desde 1994, através da Lei n. ${ }^{\circ}$ 8955/94. Sua situação, em relação aos demais, entretanto, é excepcional. O contrato de factoring, por exemplo, não possui lei que o regule especificamente, tendo apenas sua definição sido dada pelo BACEN (Banco Central do Brasil) na Resolução n. ${ }^{\circ}$ 2144/95. O mesmo ocorre com o contrato de leasing, que somente está previsto na lei para fins de tributação, sem ser, contudo, regulado e tipificado, quadro que se assemelha ao do contrato de factoring. Já quanto ao performance bond è taxa $L I B O R$, nenhuma regulação há.

Além disso, como é sabido, no caso do Brasil, não há previsão no Código
Civil vigente - e menos ainda no anterior - destes modelos contratuais. Entretanto, cabe considerar que tais contratos têm uso corrente em nosso país, tal como em diversos outros. Cumpre lembrar também que muitos destes outros países que se valem destes contratos igualmente não os têm previstos formalmente em seu ordenamento jurídico. Seu uso diário, contudo, não resta obstaculizado, sendo, em verdade, essencial para a dinâmica econômica protagonizada pelas diversas sociedades que deles vêm se valendo nos últimos anos. ${ }^{6}$

A possibilidade de seu uso rotineiro nas transações econômicas no solo desses países se dá através de dois fatores distintos, mas intimamente relacionados: a) a inserção da economia nacional em um mercado globalizado ${ }^{7}$ e, assim, a adoção, por parte desta, de modelos contratuais uniformemente aplicados

5 A respeito da adequada função e articulação do ordenamento jurídico, consulte-se: BOBBIO, Norberto. Teoria dell'ordinamento giuridico. Torino: Giappichelli, 1960.

6 Estes contratos atípicos, tendo incipiente tratamento legislativo recebem expressa autorização do art. 425 do Código Civil. A doutrina, no entanto, os têm auxiliado na sua caracterização e evolução. Cabe à teoria geral dos contratos dar-lhes uma feição que seja consentânea à regulamentação das formas e relações jurídicas intersubjetivas que decorrem do princípio da autonomia da vontade. Para uma visão geral sobre os contratos atípicos, consulte-se: AZEVEDO, Álvaro Villaça. Teoria geral dos contratos típicos e atipicos. São Paulo: Atlas, 2002.

7 Para Ronaldo Macedo Porto Júnior, as principais características atuais do processo de globalização podem ser consideradas as seguintes: ampliação do comércio internacional e formação de um mercado global assentado numa estrutura de produção pós-industrial; homogeneização de padrões culturais e de consumo; enfraquecimento da idéia de Estado nacional em benefício dos agentes econômicos do novo mercado global e formação de blocos comerciais. (MACEDO JÚNIOR, Ronaldo Porto. Globalização e direito do consumidor. In: SUNFELD, Carlos Ari; VIEIRA, Oscar Vilhena. (Org.). Direito global. São Paulo: Max Limonad, 1999, p. 225). 
em todo o globo, naquilo que se convencionou chamar de nova lex mercatoria, que analisaremos com mais vagar adiante; e $b$ ) a recepção destes modelos pelo direito nacional, com sua respectiva incorporação ao sistema jurídico de cada país, que tem um caráter político óbvio, posto que incorpora um modelo contratual não previsto pelo legislador.

É a respeito deste último ponto, especificamente, que se busca refletir. Sobre estas decisões que fazem valer um instituto jurídico não previsto na lei e que não apenas the dão validade, mas também regulam-no e fornecem-lhe moldes, introduzindo assim, não apenas um contrato diferente no sistema jurídico de cada país, mas também, e principalmente, implementando uma lógica econômica própria, das quais estes modelos jurídicos são apenas instrumentos. Ocorre que, quando um julgador dá validade a um modelo contratual não previsto no ordenamento jurídico, está, antes de tudo, dando validade a uma relação econômica específica, aceitando - e introduzindo em seu país - uma nova prática mercantil, dando vigência a um sistema econômico diferenciado, novo, não anteriormente previsto pelo legislador. E esta decisão possui traços que a permitem classificar não apenas como jurídica em um sentido estrito, mas também, e sobretudo, como uma decisão política. Tal decisão usualmente deveria competir aos Poderes Executivo e Legislativo e não ao Poder Judiciário, órgão cuja legitimidade para decidir em matéria de política econômica, comercial e exterior é bastante questionável.

O viés dessa prática se assenta na possibilidade de articular o sistema jurídico-político com a estrutura econômica presente na vida cotidiana, subjacente à realidade do mercado e de suas relações com os atores do Estado.

O objetivo, entretanto, não é demonstrar que certos magistrados possuem uma vinculação eventualmente ideológica a esta ou àquela corrente de pensamento; tampouco se objetiva promover qualquer espécie de denuncismo. Não se trata disso. A questão central é outra. O objetivo é que se perca uma certa ingenuidade, evidenciando-se que mesmo temas aparentemente corriqueiros resguardam consequiencias que podem ter um viés político, como é o caso do pronunciamento da magistratura sobre os contratos e institutos arrolados acima.

\section{AS NOVAS FUNÇÕES DO CONTRATO EM FACE DA MODERNIZAÇÃO JURÍDICO- ECONÔMICA}

A figura do contrato, como instituto jurídico tipicamente voltado à mediação das ações econômicas, ${ }^{8}$ tem sofrido,

8 Enzo Roppo já afirmara que "[...] o contrato é a veste jurídico-formal de operações económicas. Donde se conclui que onde não há operação económica, não pode haver também contrato". Ver: ROPPO, Enzo. O contrato. Coimbra: Almedina, 1988, p. 11. 
nestes últimos períodos, diversas alterações em sua morfologia e feições, ainda que sua estrutura básica guarde as principais características.

Assim, a indagação que este estudo propõe é aquela que tem a ver com a função do contrato enquanto "categoria ou modelo jurídico" relacionado com a ordem econômica, diante das exigências do mercado e sua operacionalidade racionalizada e mediada pelo Poder Judiciário. Quais as suas perspectivas e possibilidades (ou limites) de dar efetividade aos contratos internacionais diante da globalização econômica e da atuação do estado nacional?

A noção de contrato pode ser encarada por vários prismas, entre os quais o sociológico, o econômico e o jurídico, sem falar nas perspectivas formuladas pela filosofia. Desde os contratualistas até as concepções tradicionais reconhecidas pelo direito privado através das formulações clássicas e neoclássicas, que ganharam contornos de validade com a "era das codificações". Foi com a ênfase do liberalismo econômico, a partir de Adam Smith e do utilitarismo de Jeremy Bentham que o contrato foi erigido a uma condição fun- cional de instrumento de viabilização das trocas e da circulação da riqueza. O seu período áureo esteve identificado com o liberalismo clássico que o identificava como a mais inequívoca demonstração do princípio da autonomia da vontade.

Com o advento da sociedade moderna, o contrato passou a ser o principal instrumento de atribuição jurídica da vida econômica, ${ }^{9}$ tendendo o seu papel na contemporaneidade a se expandir diante das "novas" funções ${ }^{10}$ reservadas à sua atuação frente a uma sociedade pós-moderna e globalizada que prega a volta incontinenti de alguns princípios basilares, entre eles o da liberdade e da autonomia da vontade. Alguns autores chegam a falar num possível fenômeno da contratualização do direito como uma forma de predominância do direito contratual diante do próprio direito estatal."

A dinâmica das relações econômicas a partir da segunda metade do século XX oportunizou - ao lado de um incessante debate teórico por parte de economistas e juristas - a aplicação prática das teses formuladas tanto no campo econômico quanto ṅo campo

9 GOMES, Orlando; VARELA, Antunes. Direito econômico. São Paulo: Saraiva, 1977.

10 Basta que se tenham presentes as várias modalidades pós-modernas de contratação aliadas aos avanços tecnológicos que oportunizam o surgimento de várias formas contratuais celebradas pela Internet.

11 Sobre esse argumento consulte-se: LOBO, Paulo Luiz Netto. Direito do estado federado ante a globalização econômica. Revista de Informação Legislativa. Brasília, v. 38, n. 151, p. 95-108, jul./set. 2001, Veja-se também, WALD, Arnoldo. A contratualização do direito societário. Direito Empresarial, Concorrencial e do Consumidor, n. 3, p. 50-54, jun./ jul. 2005. 
jurídico. A figura do contrato passou a ter destaque, principalmente no cenário das trocas comerciais.

Para Jacques Ghestin, "[...] o contrato é uma noção jurídica funcional que visa principalmente à troca de bens e serviços. É um acordo de vontades destinado a produzir efeitos jurídicos onde a força obrigatória depende de sua conformidade com o direito objetivo. Deve estar em conformidade com suas finalidades objetivas, o útil e o justo".'2 Equivale a ser o "[ [...] instrumento jurídico que possibilita e regulamenta o movimento de riquezas dentro da sociedade". ${ }^{13}$ Para o professor Ricardo Lorenzetti, acolhendo lição de Mcneil, "[...] o contrato é um instrumento para a realização de atividades econômicas $[\ldots]{ }^{\prime \prime}{ }^{14}$

Cada sistema econômico é capaz de determinar o modelo de contrato que mais se adapta a regular as funções econômicas de produção, circulação, distribuição e comercialização de bens e serviços. ${ }^{15}$ Isso significa que o contrato como situação jurídica destinada à regulação da economia, tem a sua previsão ou pressuposto num sistema de normas jurídicas que se assentam hierarquizadas no ordenamento jurídico. A Constituição, o Código Civil, o Código Comercial, o Código do Consumidor além de uma série de princípios e normas esparsas - fornecem o embasamento necessário para a operacionalização dos contratos e sua dinâmica entre os agentes econômicos no mercado.

Importa reconhecer que o nosso ordenamento jurídico - recebendo o influxo dos sistemas econômicos adota o regime da livre iniciativa que está previsto na Constituição Federal, nos arts. $1^{\circ}$, IV e 170, caput, com o reconhecimento de que a livre concorrência é princípio geral da atividade econômica, conforme disposto no seu inciso IV. ${ }^{16}$

12 GHESTIN, Jacques. Le contrat en tant qu'échange économique. Revue d'Economie Industrielle, n. 92, p. 81-100, 2000, Numéro special, Économie des Contrats: Bilan et Perspective.

13 MARQUES, Cláudia Lima. Contratos no Código de Défesa do Consumidor: o novo regime das relações contratuais. São Paulo: Revista dos Tribunais, 2005, p. 36. No mesmo sentido: MARTINS COSTA, Judith Hoffmeister. A reconstrução do direito privado: reflexos dos princípios, diretrizes e direitos fundamentais constitucionais no direito privado. São Paulo: Revista dos Tribunais, 2002, p. 631.

14 LORENZETTI, Ricardo. Tratado de los contratos. Buenos Aires: Rubinzal-Culzoni, 1999 , v. 1, p. 19.

15 GHERSI, Carlos Alberto. Contratos: problemática moderna. Mendoza: Cuyo, 1996, p. 17-18.

16 Conexo a este princípio de ordem geral está reconhecido o direito à propriedade, previsto na mesma Constituição, nos arts. $5^{\circ}$, XXII a XXVI e 170, II. O art. 524 do Código Civil caracteriza os efeitos gerais do direito de propriedade. 
Desse arcabouço constitucional retiraram-se os fundamentos para informar todo o ordenamento jurídico direcionando as normas que visam regular a chamada "economia liberal capitalista," 17 também chamada de economia de mercado. Há que se reconhecer, no entanto, que com a crescente intervenção do Estado na atividade econômica, a partir das primeiras décadas do século $\mathrm{XX}$, as normas jurídicas passaram, cada vez mais a relativizar o conceito puro de economia liberal, nos moldes concebidos nos séculos anteriores. ${ }^{18}$

Assim, o reconhecimento do contrato, como instrumento do direito privado, apto a mediar as transações entre particulares, consagrando aquilo que a livre e autônoma disposição de vontade das partes declarou, torna possível o fun- cionamento de um sistema econômico, juridicamente reconhecido e integrado, que se desenvolve num locus denominado mercado, ainda que imaginário como quer Carlos Alberto Ghersi. ${ }^{19}$

O marco do direito privado é capaz de apresentar uma série de mecanismos aptos a serem acionados e integrados a determinado sistema econômico. Assim é comum encontrarmos uma rede muito ampla e complexa de processos normativos que tendem a refletir o espírito liberal que é reconhecido e adotado entre nós.

Com a globalização da economia e a crescente expansão dos mercados integrados busca-se uma maior harmonização das legislações com vistas a modelar a noção de contrato em níveis mais amplos. ${ }^{20}$ Tal necessidade se impõe devido a uma crise na noção de tipos

17 Carlos Alberto Ghersi prefere nominar a economia capitalista de "economia capitalista de acumulação privada", conforme GHERSI, Contratos..., p. 18 e seguintes.

18 Miguel Reale cunhou a expressão "social-liberalismo" visando uma distinção face ao neoliberalismo de Friedman e Hayek, dado que estes consideram a justiça social como um termo sem sentido (meaningless). Conforme Reale, o social-liberalismo é, em suma $o$ resultado da convergência entre a herança liberal e a socialista, e, por ser o resultado natural de um processo histórico, surge desprovido de preconceitos e antagonismos abstratos, obedecendo às exigências e conjunturas de cada povo rumo à democracia social. (cf. REALE, Miguel. O estado democrático de direito e o conflito das ideologias. São Paulo: Saraiva, 1998). A tese é também assumida por: MERQUIOR, José Guilherme. $O$ liberalismo: antigo e moderno. Rio de Janeiro: Nova Fronteira, 1991.

19 Carlos Alberto Ghersi afirma que o ato econômico é institucionalizado pelo contrato (GHERSI, op. cit., p. 29).

20 Carlos Alberto Ghersi diz: "El derecho - como consecuencia de la economía - se está volviendo cada día más global, quebrando las fronteras nacionales y de esta forma, los sistemas jurídicos de los países comienzan a ser decrecientes por su expansión a la caída de las empresas - de diversa índole verbigracia productora de bienes y servicios o financiera, etc. - hace que estos agentes económicos requieran marcos regulatorios para los mercados cada vez más homogéneos. Esta homogeneidad como sabemos se logra a través de dos mecanismos básicos: la coordinación internacional de normativas básicas 
contratuais fechados que foram legados pelos processos de codificação desde o século XIX.

A noção de contratação tradicional, baseada numa matriz racional-individualista foi moldada no período anterior à Revolução Industrial. Por esta perspectiva o contrato assegurava a mediação de troca econômica lastreada num sistema econômico artesanal que atribuía valor a cada objeto produzido individualmente e, portanto, negociado de forma isolada. O incremento da sociedade industrial e o avanço do modo de produção capitalista - associado às novas técnicas ${ }^{21}$ e à criação de um mercado de massas consumidoras faz com que a contratação tradicional seja substituída por um modelo de contratação onde ocorre a adesão (conforme suas modalidades) dos agentes econômicos às cláusulas e condições gerais apresentadas pelos empresários $^{22}$ nos vários negócios jurídicos que se estabelecem. ${ }^{23}$

Com o boom do capitalismo (industrial num primeiro momento e financeiro, numa etapa posterior) ao longo do século XX, houve um incremento das relações econômicas e contratuais. A criação de novos produtos numa escala de produção ilimitada e o alargamento dos mercados consumidores demonstra que o modelo de contratação tradicional já não é mais suficiente para contemplar todas as modalidades negociais exigidas numa sociedade em contínua e rápida transformação.

Os próprios limites tradicionais do direito civil estão, em verdade, sendo superados pela via econômica, que, em certo sentido, ultrapassa os limites da

o la imposición por organismos internacionales como el FMI o BID, etc. Pensamos que ambas herramientas están en este momento funcionando. Esta internacionalización del derecho es un fenómeno que se ha reforzado a partir de esta década de los 90 y muy especialmente en los mercados financieros, de alli que pensamos que se está gestando un nuevo orden jurídico globalizado. En este sentido los contratantes tampoco pueden obviar el conocimiento al menos en sus reglas elementales del funcionamiento normativo que se va imponiendo". (Ibidem, p. 28).

21 Ronaldo Porto Macedo Jr. refere: "O crescimento das estruturas pós-fordistas de organização da produção e circulação de mercadorias é um fenômeno mundialmente reconhecido pela literatura especializada. Diversos têm sido os modelos utilizados para a descrição destas mudanças, como o pós-fordismo, a especialização flexivel, a formação de networks produtivas, toyotismo, etc.". (MACEDO JÚNIOR, Ronaldo Porto. Contratos relacionais no direito brasileiro. Disponivel em: <http://136.142.158.105/ LASA97/portomacedo.pdf>p. 1).

22 A própria noção de "empresa" e "empresário" se afirma com o modo de produção capitalista. A esse respeito consulte-se GALGANO, Francesco. Las instituciones de la economía capitalista. Barcelona: Ariel, 1990.

23 GHERSI, Contratos..., p. 31 et seq. 
própria atividade política. ${ }^{24}$ Diante do alargamento das fronteiras nacionais e da formação dos blocos econômicos regionais ou globais, a própria noção tradicional de soberania passa a ser flexibilizada, ${ }^{25}$ o que é expresso inclusive pelo diagnóstico da ascensão de uma nova lex mercatoria. Tanto isso é verdade que começa a existir uma preocupação com a inter-relação de modelos jurídicos e negociais capazes de oferecer uma certa homogeneidade e facilidade de assimilação e integração dos sistemas jurídicos.

Pode-se dizer que nas últimas três décadas o conceito de contrato tornouse fundamental para compreender a análise econômica do direito. ${ }^{26}$

Nessa perspectiva, o surgimento de novos direitos contratuais pode destacar, no cerne do núcleo do conceito de contrato a própria noção de economicidade que o anima, vinculando-o a determinado modelo econômico da época em que se forma. ${ }^{27} \mathrm{Na}$ perspectiva do sistema capitalista as transações econômicas são concebidas para gerar valor (trabalho, renda, produção, excedente, lucro) e é através do contrato que este valor é transferido de um para outro particular. ${ }^{28}$

Ricardo Lorenzetti atribui ao contrato dois aspectos relacionados com o tipo contratual: a estrutura e a função. O primeiro aspecto é fornecido pela regulação de cada modalidade contratual (parte especial) de acordo com sua conformidade ao estabelecido na parte geral. O segundo aspecto - a função se traduz da seguinte forma: "A função descreve a finalidade prático-jurídicoeconômica que se requer do contrato, isto é, a denominada causa objetiva ou econômico-social". 29

Para novos tempos, novos instrumentos capazes de responder às crescentes necessidades econômicas e sociais. Os contratos eletrônicos e os contratos relacionais são exemplos de situações novas que vieram com a globali-

24 FERRI, Giovanni B. La 'cultura' del contratto e le strutture del mercato. In: A L'EUROPE du troisième millénaire: mélanges offerts à Giuseppe Gandolfi : à l'occasion du dixième anniversaire de la fondation de l'Académie. [s.l.]: [s.n.], 2004, v. 1, p. 385-416.

25 Ver: BERARDO, Telma. Soberania: um novo Conceito? Revista de Direito Constitucional e Internacional, São Paulo, n. 40, p. 26-29, jul./set. 2002; MCGREW, Anthony. "A global society?" In: HALL, Stuart; HELD, David; MCGREW, Antony. Modernity and its futures. Cambridge: Polity, Open University, 1992.

26 São representativos da vasta bibliografia disponível: COOTER, Robert; ULEN Thomas. Law and economics. [s.1.]: Addison Wesley Longman, 2000; POSNER, Richard. Economic analysis of law. Aspen, 2002 e SHAVELL, Steven M. Foundations of economic analysis of law. Harvard: Belknap, 2004.

27 MARQUES, Contratos..., p. 35.

28 GHERSI, op. cit., p. 30.

29 GHERSI, Contratos..., p. 20. 
zação da economia. Os primeiros porque associados às novas tecnologias que imprimem um ritmo variado e desconcertante nas transações, onde a virtualidade e o real time são condições de sua própria existência. Os outros, devido ao aumento crescente das relações de consumo que se tornaram massivas e necessitam de uma continuidade, para tornar os seus consumidores cativos das necessidades que foram criadas pela mídia, pelo marketing. São contratos que oportunizam a múltipla variação das condições e dos modos de prestação. Como diz o próprio Macedo Júnior, "a própria possibilidade do estabelecimento de um standard objetivo e prefixado para o reajuste, tal como formalizado pela teoria neoclássica, começa a se demonstrar insuficiente em face do aumento expressivo do grau de contingencialidade e variação dos termos das relações contratuais". ${ }^{30}$

As novas modalidades e figuras contratuais com certeza serão objeto de análise detida por parte do Poder Judiciário que acompanhará os seus desdobramentos conceituais e operacionais dando-lhes interpretação consentânea com a realidade política e econômica na qual se inserem e de acordo com a função ao qual estão comprometidos.

A incidência cada vez maior de operações econômicas globais - fluidas e dinâmicas - oportunizou uma diversidade muito grande de novos modelos contratuais que fogem às concepções clássicas forjadas ao longo dos séculos.

A noção de sociedade multifacetária, apoiada em níveis tecnológicos e informativos (o que convencionou chamar-se de sociedade da informação) cada vez mais crescentes que garanta altos níveis de produção capitalista dirigida à satisfação de massas consumidoras em diversos setores, faz com que novos instrumentos contratuais surjam para assegurar maior dinamicidade nas trocas mercantis.

Neste particular a economia e a sociologia têm sido instrumentos úteis no auxílio da análise jurídica para compreender este fenômeno que atinge o cerne da dinâmica e mudança dos mercados (isolados ou integrados).

Os mercados são redes complexas que estabelecem e ressaltam as contradições existentes nas estruturas sociais, de acordo com o modo de produção capitalista presente nas sociedades industriais. Para Ronald Coase "os mercados são instituições que existem para facilitar o intercâmbio, isto é, existem para reduzir os custos, o que implica a realização das transações". ".1 Nesse sentido está presente uma valoração econômica das trocas que alicerça todo o mercado, enquanto instituição.

Os mercados centralizam uma série de processos de produção, distribuição e consumo de bens e serviços de toda ordem, direcionados à satisfação indivi-

30 MACEDO JÚNIOR, Globalização.... p. 233.

31 COASE, Ronald. La empresa, el mercado y la ley. Madrid: Alianza, 1994, p. 14. 
dual e coletiva, devem existir mecanismos hábeis a estipular controles que possam estar a serviço de um interesse mais amplo como o da própria sociedade. ${ }^{32}$ Que mecanismos de controle podem ser estabelecidos sobre o mercado? De que modo o Direito pode flexibilizar a dinâmica ortodoxa dos mercados para torná-los mais "sociais" ou "abertos" a uma função social? Mecanismos que ofereçam condições de controle sobre o mercado. Um controle social e racional capaz de afirmar uma nova sociabilidade que afirme a liberdade de cada indivíduo e dos grupos e não somente a propriedade de poucos.

Toda a atividade interventiva do Estado, no modelo capitalista, pressupõe a utilização de um arcabouço jurídico-formal para controlar e legitimar as opções e medidas de regulação dos mercados. ${ }^{33}$ Esse fato é reforçado pelo caráter mutável e transformador dos mercados como condição de competitividade e lucro para garantir o processo de acumulação do capital.

Por outro lado, há uma inovação cada vez maior na produtividade industrial que busca na competitividade das empresas formas de rentabilidade e lucro. Fala-se, no âmbito da ciência econômica, com repercussões jurídicas na teoria da firma ${ }^{34}$ que apresenta as características de desenvolver uma série de transações econômicas diversificadas tanto nacional quanto internacionalmente, amparadas em uma diversidade de contratos de longa duração, como são os exemplos fornecidos por Ricardo Lorenzetti, ${ }^{35}$ Cláudia Lima Marques $^{36}$ e Ronaldo Porto Macedo Júnior ${ }^{37}$ das networks ou redes contratuais. ${ }^{38}$

32 Interessante consultar a seguinte obra: NUSDEO, Fábio. Fundamentos para uma codificação do direito econômico. São Paulo: Revista dos Tribunais, 1995.

33 NUSDEO, Fundamentos..., p. 116 et seq.

34 A este respeito, consulte-se o texto já clássico: COASE, Ronald. The nature of the firm. Economica, 4, 1937.

35 LORENZETTI, Tratado de los..

36 MARQUES, Contratos....

37 MACEDO JÚNIOR, Globalização...

38 As chamadas "redes contratuais" são aquelas que têm no contrato o instrumento apto a servir de "conexão", operações jurídicas objetivando a realização de operações econômicas as mais variadas como as relações de consumo entre grupos de fornecedores e consumidores, as relações inter-empresariais que incluem redes associativas e cadeias contratuais e de terceirização (LORENZETTI, op. cit., p. 43). O mesmo Lorenzetti conclui: "as redes são possiveis, entre outras coisas, pela crescente homogeneidade global dos padrões de produção e de consumo" (Ibidem, p. 42). Junto à noção de redes contratuais está presente a noção de complexidade que alimenta o sistema. Esta complexidade está conectada ao nível de massificação do consumo que necessita de uma rede de contratos capazes de dar vazão aos interesses privados em jogo. A teoria das redes contratuais 


\section{A NOVA LEX MERCATORIA E SEUS INSTITUTOS}

Cada vez mais as relações entre Direito e Economia ${ }^{39}$ tendem a se estreitar. Este estreitamento é diretamente proporcional ao nível acelerado do processo de internacionalização da economia que, a cada momento, cria novas condições de análise e da dinâmica capitalista.

Se os fenômenos econômicos têm sido rápidos e constantes, com mutações e adaptações a dadas realidades, o mesmo não se pode dizer do Direito. Pela sua característica formal e de ser um instrumento à garantia da estabilidade social, o Direito tem-se deparado com algumas dificuldades de encontrar "novas saídas" ante "novas realidades" econômicas. Tais dificuldades se dão não só no momento da produção do Direito, como também na sua consolidação através da aplicação e interpretação das normas jurídicas. O raciocínio jurídico-institucional tem sido relativa- mente lento em face da dinâmica econômica operada pelo mercado. ${ }^{40}$

Falar sobre uma nova lex mercatoria pressupõe, obviamente, a existência de uma antiga lex mercatoria, ou seja, um exemplo histórico pretérito a que remeta a prática atual, extraindo deste o seu significado e buscando-se nele o nome para o fenômeno recente. Como ensina Francesco Galgano, esta "expressão tem origem culta: quer aludir ao renascimento, na época moderna, de um direito tão universal quanto foi o direito dos mercadores medievais". ${ }^{41}$ Aqui, vale lembrar, antes de tudo, a lição do referido mestre italiano, para quem a característica central do ius mercatorum é o particularismo. ${ }^{42}$ Assim, tem-se o seguinte: “É, na origem, o ius mercatorum ou lex mercatoria, e é tal não só porque regula a atividade dos mercadores, mas também, e sobretudo, porque é direito criado pelos mercadores, que nasce dos estatutos das corporações mercantis, do costume mercantil, da jurisprudência da

encontra respaldo na base dos chamados contratos relacionais que teve início no sistema de common law. Os contratos relacionais compreendem duas situações simultâneas: os vínculos de longa duração e as redes contratuais.

39 GRAU, Eros Roberto. O direito posto e o direito pressuposto. São Paulo: Malheiros, 2002, p. 44-59.

40 FARIA, José Eduardo (Org.). Direito e globalização econômica: implicações e perspectivas. São Paulo: Malheiros, 1998. Ver também: FARIA, José Eduardo. Direito na economia globalizada. São Paulo: Malheiros, 2000.

41 GALGANO. Francesco. La nuova lex mercatoria In: Atlante di diritto privato comparato. Bologna: Zanichelli, 1995, p. 42.

42 GAlgANO, Francesco. Lex mercatoria. Revista de Direito Mercantil, Industrial, Econômico e Financeiro. São Paulo, v. 129, 2003, p. 224. 
corte dos mercadores. É ius mercatorum, diretamente criado pela classe mercantil, sem mediação da sociedade política, imposto a todos em nome de uma classe, não já em nome da inteira comunidade [...]." ${ }^{43}$ Tem-se, desta forma, um direito com aspirações de autonomia, sendo esta autonomia aqui entendida no sentido de uma liberdade positiva coletiva, ${ }^{44}$ um regrar-se a si próprio no qual tanto os destinatários das normas quanto os elaboradores dessas mesmas normas se confundem, são a mesma pessoa ou, no caso em tela, o mesmo grupo de pessoas - os mercadores. Um direito criado para e pelos mercadores dentro de uma lógica própria avessa à mediação política e aos estados nacionais, voltado essencialmente para um fenômeno econômico em constante expansão. Um direito, portanto, sempre "aberto às exigências da uniformidade internacional". ${ }^{45}$ Podemos, assim, entender a nova lex mercatoria à semelhança de sua predecessora, como " $[. .$.$] um direito com$ caráter meta-nacional, cujo raio de ação tende a coincidir com os mercados internacionais". ${ }^{46}$ Desta maneira, o que se tem é um direito que pretende ser aplicado de modo praticamente idêntico em todos os cantos do mundo.

O que não se pode perder de vista, entretanto, a despeito da uniformidade jurídica, é a uniformidade econômica que a causa e acompanha. Unidade econômica essa que toma corpo a partir de um determinado modelo econômico que busca sua expansão (e que gerou sua hegemonia), e que se coloca diante de cada economia nacional como uma "alternativa" - por vezes irrecusável e irresistível - aos modelos preconizados por cada sociedade política nacional. Entretanto, essa universalidade de um mesmo sistema jurídico e econômico não é obtida somente através da celebração, por parte do Poder Executivo, de tratados internacionais. Lembra-nos mais uma vez Francesco Galgano:

O que domina a cena jurídica do nosso tempo não são as convenções internacionais de direito uniforme, nem são, no âmbito europeu, as diretivas comunitárias de harmonização do direito dentro da União. O elemento dominante é, muito antes, a circulação internacional de modelos contratuais uniformes. São, no mais das vezes, contratos atípicos: quem os cria não são os legisladores nacionais, mas são os departamentos jurídicos das grandes multinacionais, são os consultores das associações internacionais de diversas categorias empresariais. O seu nome, que équase sempre um nome em inglês, testemunha a origem americana desses modelos; mas do pais de origem leasing, franchising, performance bond, etc. são

\section{Ibidem, p. 224.}

44 Esta tipologia foi adotada a partir daquela elaborada em: BOBBIO, Norberto. Igualdade eliberdade. São Paulo: Ediouro, 2000.

45 GALGANO, Lex mercatoria..., p. 225.

46 GALGANO, Lanuova..., p. 42. 
propagados para todo o planisfério. Eles não têm nacionalidade: a sua função é a de realizar a unidade do direito dentro da unidade dos mercados. ${ }^{47}$

Ralf Dahrendorf salienta que "a nação-estado era também um veículo necessário para o estabelecimento do contrato moderno no lugar da servidão feudal". ${ }^{48}$ Nada mais correto. O estado nacional e a sua continuidade jurídica interna - substituindo a descontinuidade formada pela fragmentação feudal de outrora - é um instrumento necessário à concretização da idéia de contrato, o instrumento burguês por excelência das trocas econômicas. Assim, tem-se o estado-nação como sendo nada muito diferente de uma função da idéia de contrato, tendo ele próprio, na visa moderna, se originado em um grande contrato social, como descreveram Hobbes, Rousseau e Kant, entre outros. Observa-se que essa continuidade jurídica interna - que encontra seu apogeu com o período das codificações - somente pode ser entendida desejável enquanto as vias comerciais não ultra- passarem o âmbito destes estados nacionais. Uma vez superada pela via econômica essa barreira outrora intransponível, grande parte da função legislativa para a qual nasceu o estado nacional, também se torna dispensável. Dito de outro modo: tendo nascido o estado nacional em grande medida para monopolizar a produção legislativa ${ }^{49}$ num dado contexto territorial para darThe uniformidade às práticas econômicas e jurídicas, e uma vez sendo ampliada a abrangênicia dessas relações econômicas, que se buscam uniformes, para além dos limites dos estados nacionais, por óbvio a produção legislativa escapará ao domínio do estado, sendo muitas vezes imposta a ele de fora, visando inserir-lhe num dado novo modelo econômico uniforme, do qual ele não seja mais o protagonista, mas sim apenas mais um participante.

É este o quadro atual, especialmente se considerarmos a uniformidade contratual a que Francesco Galgano se referiu anteriormente, já que estes contratos buscam regular um sistema econômico uniforme, sendo eles gerados

47 GALGANO, Francesco. Diritto ed economia alle soglie del nuovo millennio. Contrato e Impresa, Padova, v. 17, n. 1,2000, p. 199.

48 DAHRENDORF, Ralf. O conflito social moderno: um ensaio sobre a política da liberdade. Rio de Janeiro: Jorge Zahar; 1992, p. 44.

49 O monopólio legislativo dos estados nacionais, em verdade, pode ser visto como uma função de outro monopólio, ou pretensão monopolística, do Estado Nacional, qual seja, aquele que recai sobre o controle legítimo dos meios de coerção na ordem interna de um dado território, conforme a formulação clássica weberiana: WEBER, Max. Ciência e política: duas vocações. São Paulo: Cultrix, 2004, p. 55-57. Sobre os monopólios legislativo e jurisdicional como funções da reivindicação do monopólio legítimo da coerção por parte de estados nacionais, ver: TILLY, Charles. Coerção, capital e estados europeus. São Paulo: Ed. USP, 1996, p. 157-158. 
não no interior dos legislativos nacionais, mas sim no mercado internacional, dispostos a uma aplicação idêntica no mundo inteiro. Entretanto, é oportuno observar que a gestação desses modelos contratuais é um momento que se difere da sua aplicação e, mais precisamente, de sua aceitação pelos diversos sistemas jurídicos nacionais. Trata-se, como já dito, de um momento diverso e é justamente para esse procedimento que o presente texto se volta agora.

\section{A JURISDIÇÃO DIANTE DOS CONTRATOS DA NOVA $L E X$ MERCATORIA}

Aludindo à uniformidade contratual provocada pela nova lex mercatoria, salientou Francesco Galgano: "Um primeiro terreno sobre o qual o fenômeno se manifestou é o da jurisdição. À escassa propensão dos legisladores nacionais à integração internacional do direito contrapõe-se uma diferente postura dos juízes, os quais tendem a fazerem-se órgãos de uma sociedade civil internacional integrada". ${ }^{50}$ Assim, podemos entender que as decisões que dão receptividade interna, nacional, aos contratos de leasing, franchising, factoring, etc. vêm sendo capitaneadas não pelo Poder Legislativo, a quem incumbiria a criação ou aceitação de novos tipos contratuais no ordenamento jurídico, mas sim pelo Poder Judiciário, que seria originalmente encarregado apenas de verificar sua regularidade de acordo com os padrões determinados pelo legislador. O papel da magistratura, assim, parece assumir uma feição diversa daquela para a qual nasceu. No momento em que decide sobre a validade de um modelo contratual uniformemente aplicado em grande parte do planeta, não está o julgador simplesmente verificando a sua regularidade, uma vez que praticamente inexiste marco legislativo para basilar tal julgamento. Naquele dado instante, o julgador decide não apenas se o modelo contratual atípico em questão está de acordo com as cláusulas gerais que postula o ordenamento jurídico, mas decide, principalmente, se o país a que pertence se insere ou não em determinadas práticas econômicas internacionais, até então estranhas ao seu país. E esta decisão obedece também - e provavelmente de modo determinante - a critérios de racionalidade política, não necessariamente a critérios exclusivos do mundo jurídico. Voltemos a Francesco Galgano:

Postura análoga encontra-se quando se
trata de julgar sobre a validade dos
contratos atipicos de grande difusão
internacional. Aqui ojuizo de mérito dos
interesses perseguidos, exigido pelo
direito interno, é influenciado pela
uniformidade internacional do modelo
contratual. Conquanto o juiz deva, a
rigor, exprimir esse juizo com base em
seu ordenamento, ele hesita em julgar 
inválido com fundamento nesse ordenamento, um modelo contratual em todo lugar reconhecido como válido. Ele está consciente do isolamento econômico no qual, de outro modo, colocaria o próprio país no contexto dos mercados internacionais; será levado a exprimir o juizo de mérito não em respeito unicamente ao ordenamento interno, mas com referência aos principios aceitos nas 'nações de cultura afim': o que é válido em todas essas nações não pode não ser válido na nossa nação. ${ }^{\text {I }}$

O Judiciário leva em consideração, assim, critérios de racionalidade afeitos à política: interação estratégica com vistas à racionalidade de outros atores, no caso, as pressões do mercado mundial, externas e internas, que forçam o país adotar uma dada postura no cenário internacional..$^{52}$

Nesse contexto, a posição em que se vê inserido o Poder Judiciário não difere muito daquela em que acaba também ficando o Poder Legislativo diante das negociações feitas, no plano internacional, pelo Poder Executivo, que envolvem matéria de política comercial e econômica. Uma vez sinalizada para o mercado mundial a postura que a nação adotará - o que geralmente é feito somente pelo Executivo, que mono- poliza a política exterior - ficam os demais atores da política interna condicionados - e por vezes forçados - a aceitar e a implementar essa política, mesmo que isso implique em um choque com o ordenamento jurídico e com a correlação de forças vigente no interior do país. Estudando as relações recentes entre os Poderes Executivo e Legislativo brasileiros no que concerne à política de comércio exterior, Fabiano Santos concluiu:

Ele [o Presidente da República] toma a decisão em fóruns internacionais, negociando acordos multilaterais ou bilaterais com parceiros comerciais, ou reduzindo unilateralmente as tarifas de importação de produtos estrangeiros. Quando isso ocorre, a posição do país já está de alguma maneira comprometida. Vale dizer, caso o Congresso rejeite o acordo [...] é bem provável que o país incorra nos custos decorrentes de sanções comerciais impostas pelos parceiros comerciais dominantes. Parte dos legisladores tentará de todo modo evitar este resultado, ratificando finalmente o acordo firmado pelo presidente no início do jogo. ${ }^{53}$

Tais afirmações não diferem em nada praticamente daquilo que ocorre com o Judiciário. Diante de um contrato com claras origens estrangeiras, o julgador

51 Ibidem, p. 201.

$52 \mathrm{O}$ conceito de interação estratégica, bem como o de racionalidade, que o integra, foram extraídos de: REIS, Fábio Wanderley. Política e racionalidade: problemas de teoria e método de uma sociologia crítica da política. Belo Horizonte: Ed. UFMG, 2000, p. 68-89.

53 SANTOS, Fabiano. O poder legislativo no presidencialismo de coalizão. Belo Horizonte: Ed. UFMG, 2003, p. 154. 
já se encontra condicionado a sinalizar com sua validade, mesmo que implicitamente. E a aceitação do referido tipo novo de contrato pelo direito interno acaba sendo feita via magistratura, antes mesmo de sua incorporação formal ao sistema jurídico, o que, muitas vezes, sequer acaba acontecendo.

Pode-se aventar, portanto, outra hipótese: não há carência de mediação por parte da sociedade política quanto à nova lex mercatoria, mas sim um excesso de concentração dessa mediação nas mãos dos atores executivos nacionais que agem internacionalmente, mormente os Poderes Executivos e os Bancos Centrais (corroborando, deste modo, a tese do advento da assim denominada "tecnodemocracia" ${ }^{54}$ ). Seja como for, o que se quer ressaltar é que, independentemente de ter sido professada pelo Legislativo, pelo Executivo ou pelo Judiciário, a decisão possui uma natureza que dificilmente escapa ao mundo político, uma vez que envolve manifestar-se sobre a inserção ou não do país em uma determinada lógica econômica internacional. $\mathrm{E}$ o que vem ocorrendo, no mais das vezes, é que o Poder Executivo alinha a nação no plano externo com relação a uma dada política econômica, restando aos demais atores internos - Poderes Legislativo e Judiciário - a responsabilidade de implementar essa nova diretriz, cabendo a eles a responsabilidade pelo eventual custo de rejeitar essa política por se chocar ela com a correlação interna de forças - Poder Legislativo - ou com o ordenamento jurídico - Poder Judiciário. ${ }^{55}$ Trata-se, portanto, de considerar estrategicamente a posição dos demais atores internacionais e as conseqüências que isso traria ao país. Validar ou não um contrato dessa rationale econômica é uma decisão tão política quanto a que toma o Poder Legislativo validando um acordo internacional feito pela chefia de Estado, muito embora o âmbito da atuação seja verdadeiramente diverso. ${ }^{56}$

54 GALGANO, Diritto..., p. 203.

55 A lógica do custo da rejeição após a sinalização de um compromisso gerador de conseqüências concretas também é empregada para explicar a força das Medidas Provisórias à disposição do Presidente da República no Brasil. Sobre isso, ver: FIGUEIREDO, Argelina Cheibub; LIMONGI, Fernando. Executivo e legislativo na nova ordem constitucional. Rio de Janeiro: FGV, 1999, p. 26.

56 Tratar-se-ia de verificar que o Poder Judiciário não julga somente com base em critérios estritamente legais, aventando também as possíveis conseqüências do que for decidido, em um argumento que poderia ser classificado como conseqüencialista: ATIENZA, Manuel. As razões do argumento: teorias da argumentação jurídica. São Paulo: Landy, 2002, p. 193-196. Em teoria dos jogos, dir-se-ia que o julgador, por assumir uma posição aparentemente sub-ótima, é um jogador que atua em múltiplas arenas: TSEBELIS, George. Jogos ocultos: escolha racional no campo da política comparada. São Paulo: Ed.USP, 1998, p. 17-25. 
Não é isso que se alega, entretanto, quando o Poder Judiciário se volta para analisar a aplicabilidade de contratos como os arrolados anteriormente. De praxe, a argumentação restrita ao linguajar jurídico é o que prepondera. Decide-se sobre elementos da inserção ou não do país no mercado internacional e as consequiências que isso poderia ocasionar para a economia nacional, mas raramente se utilizam estes argumentos para fundamentar o decidido, muito embora sejam justamente eles os pontos a serem observados. Na verdade, como lembra mais uma vez Francesco Galgano, o que se alega para a aceitação destes contratos é a força da autonomia da vontade de que dispõem os contratantes, presente na imensa maioria dos sistemas jurídicos. ${ }^{57}$

\section{POSSIBILIDADES DE ACEITAÇÃO DOS CONTRATOS DE UNIFORMIDADE INTERNACIONAL PELO PODER JUDICIÁRIO}

Para uma compreensão mais adequada do tema pode-se, assim, delinear três possíveis comportamentos típicoideais através dos quais os judiciários nacionais aceitam, no plano interno, um contrato internacionalmente uniforme: a) aceitação explícita: o julgador se vale de critérios políticos e econômicos, assumindo francamente as reais implicações de sua decisão, valendo-se desses argumentos para dar validade ao modelo contratual, analisando os possíveis efeitos econômicos e políticos de sua decisão no contexto geral do país; b) aceitação explícita mista: ao lado da fundamentação político-econômica, o julgador se vale de critérios jurídicos, alimentando o discurso professado pelo Direito no que concerne à autonomia contratual; c) aceitação jurídica: o julgador analisa sua decisão sob a ótica estritamente jurídica, considerando válido o contrato por força dos princípios e regras de seu próprio ordenamento jurídico, mormente a vinculação da declaração de vontade. Trata-se de perceber, em verdade, um continuum entre o que se poderia chamar de argumentação política, que centra seu objeto em juízos de fato sobre as relações econômicas entre os povos e os vê como prepotentes ao direito interno, e a argumentação jurídica, tradicional, que atenta para a legislação interna e para os princípios gerais do direito mo-

57 "A moderna lex mercatoria não é, provavelmente, senão, prática contratual internacionalmente uniforme. Do fato de ser internacionalmente uniforme decorre para ela uma notável força persuasiva sobre os juízes nacionais: mas ela permanece sempre prática contratual, vinculante dentro de cada Estado em virtude dos princípios que atribuem efeitos vinculantes aos contratos". (GALGANO, La nuova..., p. 44). 
derno, aceitando o tipo negocial pelas soluções que o próprio Direito permite. ${ }^{58}$

A atividade interventiva do Estado, no modelo capitalista, pressupõe a utilização de um arcabouço jurídicoformal para controlar e legitimar as opções e medidas de regulação dos mercados. ${ }^{59}$ Esse fato é reforçado pelo caráter mutável e transformador dos mercados como condição de competitividade e lucro para garantir o processo de acumulação do capital. Em que medida os interesses econômicos expressos na dinâmica do mercado podem ser decisivos para moldar os rumos da sociedade contemporânea?

A partir da fixação da noção de Constituição econômica foi possível elaborar um modelo institucional que passou a consolidar a experiência intervencionista nos Estados contemporâneos, cabendo ao Poder Judiciário, paulatinamente, ser chamado a manifestar-se sobre a validade dos argumentos jurídicoeconômicos levados à sua apreciação. No entanto, as opções políticas estão sempre presentes no argumento e no discurso de quem está fadado a dizer o direito. Isso para que sejam mantidas as regras do jogo, com a perspectiva da estabilidade institucional. ${ }^{60}$ Mesmo um mínimo de regras, constituindo um quadro jurídiconormativo que assegure o funcionamento do mercado é indispensável. Nos países de democracia recente a afirmação de que é necessário um quadro jurídico institucional (via de regra, através da Constituição) faz com que se legitime, ao menos aparentemente, as mudanças na ordem econômica.

Assim delineados os tipos-ideais de decisões acerca da aceitação dos contratos uniformemente internacionais no cenário nacional, pode-se passar a uma análise mais acurada do comportamento do Poder Judiciário brasileiro quanto a esses negócios jurídicos.

\section{POSICIONAMENTOS DA MAGISTRATURA BRASILEIRA}

Como parece óbvio, a magistratura brasileira não se encontra fora deste contexto, mas apresenta suas particularidades, uma vez que o comportamento freqüente e dominante da jurisprudência brasileira parece destoar daqueles propostos anteriormente. ${ }^{6 !} \mathrm{Ou}$

58 Tais categorias analíticas não foram extraídas de alguma obra que trate de forma sistematizada sobre o tema, sendo antes uma construção realizada pelos autores a partir daquilo que anteriormente foi descrito sobre a confrontação das diversas magistraturas nacionais ante o fenômeno recente da nova lex mercatoria.

59 MONCADA, Luis Cabral de. Direito econômico. Coimbra: Coimbra, 1996, p. 26.

60 Sobre estabilidade institucional através de regras que são editadas, arbitradas e cumpridas (self enforcing), consulte-se NORTH, Douglass. Institutions: institutional change and economic performance. Cambridge: Cambridge University, 1990.

61 As conclusões aqui apresentadas foram extraídas da análise da jurisprudência do Supremo Tribunal Federal (STF), do Superior Tribunal de Justiça (STJ), dos Cinco Tribunais Regionais Federais (TRF's) e do Tribunal de Justiça do Estado do Rio Grande do Sul (TJRS) e, assim, não são, nem pretendem ser, exaustivas sobre o tema. 
seja, vendo-se o que os magistrados brasileiros decidiram acerca da aceitação interna dos contratos de leasing, franchising, factoring, performance bond, o que se obtém é um padrão distinto. A aceitação desses contratos no Brasil parece não se dar através de procedimentos como a aceitação explícita, a aceitação mista e a aceitação juridi$c a$, mas sim pelas vias daquilo que poderia ser chamado de aceitação implicita, caso no qual o julgador, ao se deparar com um contrato novo como estes, ignora a novidade que este contrato atípico representa, considerando-o como se já tivesse sido aceito em seu país. Não há, portanto, um julgamento acerca da validade, da aceitação ou não, daquele dado contrato por parte do país em que se julga. $O$ que se apresenta são casos em que a magistratura julga sobre esses contratos, atendo-se a julgar requisitos formais de adequação do contrato, como se já houvesse uma regulação a seu respeito, como se eles já estivessem previstos no ordenamento jurídico.

Alguns exemplos servem para melhor ilustrar o alegado.

O contrato de franchising (ou contrato de franquia) se encontra regulado pela Lei $n .{ }^{\circ} 8955$, desde 15.12.1994 e não haveria, portanto, que se falar em uma regulação anterior a esta data, uma vez que a lei específica determinou seus requisitos essenciais somente a partir de então. Entretanto, observando a jurisprudência do hoje extinto Tribunal de Alçada do Estado do Rio Grande do Sul, encontra-se um julgado que menciona este modelo contratual, fazendo-lhe análise dos seus requisitos de validade antes da vigência da referida lei. O julgado - e lembrese, em segunda instância, o que atesta a celebração do contrato tempo significativamente anterior ao do julgamento - data de 31.05.1994 e é, como se vê, anterior à lei que regulamenta o franchising no Brasil. ${ }^{62}$ Neste julgado, inexiste menção ao fato de não haver aquele dado contrato em nosso sistema jurídico, e a análise se limita aos requisitos contratuais de validade, aceitando-o como válido e vigente em nosso sistema jurídico ex ante, sem qualquer consideração quanto a isso pelo julgador.

Nos demais casos isso se torna provavelmente mais flagrante, dada a ausência, ainda hoje de regulação quanto a esses negócios. Salvo o caso do contrato de franquia (frachising), cuja lei o define $e$ regula, a previsão destes contratos, geralmente, se encontra feita na legislação, mas tão só para fins tributários e o que se define geralmente é um conteúdo mínimo, bastante limitado. O caso do contrato de performance bond, por exemplo, torna ainda mais claro o modelo proposto de "aceitação implícita", uma vez que se decide sobre a sua validade sem sequer haver a referida definição do que seja tal con-

62 Trata-se aqui do RIO GRANDE DO SUL. Tribunal de Alçada. Nona Câmara Cível. Recurso de Apelação Cível n.. 194050779. Relator João Adalberto Medeiros Fernandes. 
trato, nem mesmo para os aludidos fins tributários. Mesmo o STJ já se pronunciou sobre a validade e a regularidade de dois desses contratos sem que haja qualquer marco legal a respeito deles. ${ }^{63}$

$\mathrm{O}$ mesmo se dá com o contrato de leasing, com a diferença de que ele está definido em lei para fins fiscais, tendo, contudo, centenas, senão milhares de processos a seu respeito no Brasil inteiro, não havendo, entretanto, nada que o regule e que determine seus contornos legais. Já o contrato de factoring também se encontra definido pela lei, sem que haja sua regulação mais precisa. Na verdade, a sua definição já foi feita em dois momentos, encontrandose tanto na Lei n. ${ }^{\circ} 8.981 / 95$, que novamente - tem fins tributários, e na Resolução 2144/95 do BACEN, que lhe dá caráter de atividade comercial e não financeira. ${ }^{64}$ Ressalte-se que essa regulação feita pela autoridade monetária corrobora a tese de que os bancos centrais são cada vez mais os protagonistas de um novo e cada vez mais presente cenário, que anteriormente foi denominado tecnodemocracia.

Interessante é observar algo mencionado ao início deste texto. A chamada taxa LIBOR (London Interbank Offered Rate) é uma taxa preferencial de juros oferecida para grandes empréstimos entre os bancos internacionais que operam com euros e dólares, taxa esta que varia de acordo com o mercado internacional. A taxa $L I B O R$ é geralmente a base para outros grandes empréstimos em euros e dólares a empresas e instituições governamentais com avaliação de crédito inferior, vistas como vulneráveis, inseguras ou não confiáveis. Segundo essa definição, portanto, um país de Terceiro Mundo pode ser obrigado a pagar um ponto acima da taxa $\angle I B O R$ quando contrair empréstimos. Convém observar que a jurisprudência brasileira vem dando aplicabilidade a esta taxa, não a considerando estranha aos índices aqui comumente praticados, sendo vista como decorrente de um percentual flutuante, não uma imposição do credor ao devedor, desde que devidamente ajustada entre as partes. A jurisprudência do STJ já se pronunciou neste sentido. ${ }^{65} \mathrm{Como}$ se observa, ali não há o que anteriormente foi denominado aceitação implícita, mas sim uma aceitação jurídica, posto que o decidido se funda essencialmente na validade da declaração das vontades dos acordantes.

Com isso, pode-se observar que o padrão de comportamento da magistra-

63 Trata-se dos BRASIL. Superior Tribunal de Justiça. Primeira Turma. Recursos Especiais $n^{\circ}$ 476.450. Relator: Luiz Fux. e BRASIL. Superior Tribunal de Justiça. Quarta Turma. Recurso Especial n²5 1.438, Relator: Barros Monteiro.

64 Trata-se de conclusão extraída do julgamento do BRASIL Tribunal Regional Federal $2^{a}$ Região. Primeira Turma. Mandando de Segurança n 9902288090 . Relator: Ricardo Regueira. 65 Trata-se dos BRASIL. Superior Tribunal de Justiça. Quarta Turma. Recurso Especial n. ${ }^{\circ}$ 11.593. Relator: Barros Monteiro. e BRASIL. Superior Tribunal de Justiça. Quarta Turma. Recurso Especial n 164.929, Relator: Sálvio de Figueiredo Teixeira. 
tura brasileira é o seguinte: não se declarar politicamente mesmo quando assim se decide. Aceitação implícita ou jurídica - nos termos utilizados aqui seja como for, a magistratura brasileira parece ser avessa a se declarar como um agente político, mesmo quando assim age. No mais das vezes, quando a magistratura brasileira lança mão de argumentos não jurídicos em temas afeitos a este, o faz em prol da situação de fato gerada pela inserção econômica internacional do país, desfavorecendo o sistema jurídico pátrio. Dois exemplos podem ser extraídos diretamente da jurisprudência. O primeiro remete novamente a um julgado do STJ no qual os atos de soberania são equiparados aos fatos da conjuntura internacional para fins de aplicação do direito, considerando-os fontes equivalentes de direito. ${ }^{66}$ Argumento semelhante se verifica em outro julgado do STJ, cujo trecho se encontra a seguir: "Sendo o princípio da não-discriminação tributária adotado na ordem interna, deve ser adotado também na ordem internacional, sob pena de desvalorizarmos as relações internacionais e a melhor convivência entre os países". ${ }^{67}$ Podemos identificar aqui um argumento que embasa a decisão no qual o julgador se despe de uma racionalidade jurídica própria, dando voz ao que se poderia chamar de uma lógica política de interação estratégica, tal qual delineado anteriormente, na qual o julgador tem ciência das conseqüências mais amplas que pode gerar a partir de um determinado tipo de posicionamento. Estes momentos, nos quais o julgador se declara abertamente e decide de acordo com uma racionalidade que foge aos limites forenses, contudo, são raros e praticamente nã̃o há referência a eles quanto aos contratos da nova lex mercatoria, como se observou.

Ainda em tempo, cumpre observar o modelo de análise proposto por Carlo Guarnieri e Patrizia Pederzoli. De acordo com eles, ao se analisar o poder da magistratura dentro de um dado sistema político, deve-se atentar para três dimensões básicas, quais sejam: a) os métodos de recrutamento e formação da magistratura, bem como as eventuais tendências de ativismo por parte dos julgadores; $b$ ) a estrutura e a organização judiciárias internas, bem como o seu arranjo institucional e seus recursos de intervenção no interior dos demais poderes; e c) o próprio sistema político, se mais concentrado ou mais fragmentado. ${ }^{68}$ Aplicando o modelo ao es-

66 Trata-se do BRASIL. Superior Tribunal de Justiça. Primeira Turma. Recurso Especial n. ${ }^{\circ}$ 549.873. Relator: Luiz Fux.

67 Extraído do BRASIL. Superior Tribunal de Justiça. Primeira Turma. Recurso Especial n. ${ }^{\circ}$ 426.945. Relator: Teori Albino Zavascki.

68 GUARNIERI, Carlo; PEDERZOLI; Patrizia. La puissance de juger: pouvoir judiciaire et démocratie. Paris: Michalon, 1996. 
tudo aqui empreendido, o qual se focou no primeiro destes tópicos, pode-se afirmar que as tendências ao ativismo judicial manifestadas pela magistratura brasileira, neste tópico específico, são praticamente nulas, não havendo que se falar em obstrução à vigência dos institutos da nova lex mercatoria no Brasil pelo Poder Judiciário.

\section{CONCLUSÃO}

Isto posto, faz com que duas conclusões sejam alcançadas quanto ao que vem decidindo o Poder Judiciário no Brasil em matéria dos tipos negociais da nova lex mercatoria. Em primeiro lugar, ao que parece, quando se decide sobre a vigência desses modelos contratuais no plano interno, a opção que tem sido realizada é aquela que aponta no sentido de se dar validade a eles, ainda que se conceda essa validade sem que se declare isso. O tipo contratual é válido desde o início e tem características próprias, mesmo que não haja uma lei que o regule. E quando há, somente o que se vê é uma regulação mínima do contrato, ou seja, sua definição para fins de tributação. Em segundo lugar, decidindo em favor da vigência destes contratos-e, portanto, em favor de uma dada racionalidade econômica da qual estes contratos são meros instrumentos - tem o Judiciário brasileiro, ainda que tacitamente, como se tentou mostrar, anuído com as sinalizações da política externa comercial do país, não se apresentando como um obstáculo à internacionalização da economia nacional que tem sido levada a cabo, ao longo dos últimos anos, pelo Poder Executivo. ${ }^{69}$

Em verdade, este último ponto merece alguma consideração. Certos autores têm se apresentado temerosos quanto aos reflexos que o Poder Judiciário pode trazer à economia brasileira, seja por intervir diretamente nela de modo prejudicial e casuístico, seja por atentar contra os atores deste processo, mormente o Poder Executivo e suas agências. ${ }^{70}$ Tais críticas afirmam

69 WERNECK VIANNA, A judicialização..., p. 10.

70 Como exemplos disso, pode-se citar: ARANTES, Rogério Bastos. A crise do judiciário no Brasil. Trevisan, São Paulo, n. 104, 1996; ARANTES, Rogério Bastos. Judiciário e política no Brasil. São Paulo: Idesp, 1997; ARANTES, Rogério Bastos. Judiciário e democracia no Brasil. Novos Estudos CEBRAP, São Paulo, n. 54, 1999; BALBINOTTO NETO, Giácomo. Os reflexos das decisões judiciárias na economia. Palestra no Tribunal Regional Federal da $4^{a}$ Região, 2004. Guarde-se atenção especial para o incessante trabalho de pesquisa de Armando Castelar Pinheiro, que nos últimos anos produziu uma série de artigos sobre o tema, entre os quais destacamos os seguintes: PINHEIRO, Armando Castelar. A reforma do judiciário: uma análise econômica. In: BRESSER PEREIRA, Luiz Carlos; WILHEIM, J.; SOLA, Lourdes (Org.). Sociedade e estado em transformação. São Paulo: UNESP, 2001; PINHEIRO, Armando Castelar; CABRAL, Célia. Credit markets in brazil: the role of the judiciary and other institutions. In: PAGANO, M (Org.) Defusing default: incentives and institutions. [s.1.]: DB/OCDE, 2001; PINHEIRO, Armando Castelar. 
que os posicionamentos do Poder Judiciário brasileiro reduzem a eficiência econômica, uma vez que seria ele um ator institucional com poder de veto das políticas majoritárias e que sua interferência excessiva incrementaria os custos de transação de qualquer investidor no país, gerando incerteza. ${ }^{71}$ Isto o transformaria em um obstáculo tanto à governabilidade quanto à calculabilidade econômica, ambas afeitas à idéia de segurança jurídica, tida como necessária àqueles investimentos.

Pelo que restou aqui demonstrado, contudo, o Poder Judiciário brasileiro não tem se apresentado como um entrave aos gestores da economia nacional. Observou-se que a internacionalização da economia do país, sinalizada há mais de uma década pelo Poder Executivo, não tem sido obstaculizada pelas decisões judiciais, sendo as práticas da nova lex mercatoria majoritariamente aceitas pela magistratura nacional. Outros estudos também já demonstraram que as diretrizes preconizadas pelas instituições majoritárias não têm sido objeto de intervenção do Poder Judiciário nacional. ${ }^{72}$

As críticas que aqueles autores dirigem ao Poder Judiciário, como se um certo casuísmo dos julgadores fosse uma das fontes da ineficiência econômica nacional, não merece ser direcionada diretamente à magistratura, mas, ao que parece, à estrutura judiciária que a circunda e dentro da qual ela decide. É esta que gera morosidade e que acaba ocasionando incertezas, trazendo muitos dos problemas delineados por aqueles autores. As tendências ao ativismo foram os pontos sobre os quais tratou este artigo e, como se verificou, elas restam bastante esparsas, não parecendo haver nem casuísmo, nem politização por parte dos julgadores. Pelo contrário, se há alguma tendência, esta parece ser nitidamente não-interventiva. A crítica

Direito e economia num mundo globalizado: cooperação ou confronto? In: ANDRADE, Rogério E. de. (Org.). Regulação pública no Brasil. Campinas: Edicamp, 2003 e PINHEIRO, Armando Castelar. A relação entre o desempenho das instituições jurídicas e o crescimento econômico. In: WALD, Arnold.; MARTINS, Ives Gandra S. e PRADO, N. (Org.). O direito brasileiro e os desafios da economia globalizada. São Paulo: América Jurídica, 2003.

71 A idéia de ser o judiciário um ator político com capacidade de bloquear as políticas majoritárias foi extraída de: TSEBELIS, George. Veto players: how political institutions work. Princeton: Princeton University, 2002. O conceito de custos de transação e a idéia de instituições políticas como suas redutoras para fomentar a atividade econômica foram extraídos de: NORTH, Institutions..., p. 3-69.

72 Ver, por exemplo: CASTRO, Marcus Faro de. O Supremo Tribunal Federal e a judicialização da política no Brasil. Revista Brasileira de Ciências Sociais, São Paulo, v. 12, n. 34, 1997; WERNECK VIANNA, A judicialização...; OLIVEIRA, Vanessa Elias de. Judiciário e privatizações no Brasil: existe uma judicialização da política? Dados, Rio de Janeiro, v. 48, n. 3, 2005. 
dirigida por aqueles autores, que eles frequientemente apontam indistintamente ao Poder Judiciário, poderia ser melhor compreendida se fosse dirigida não aos posicionamentos da magistratura, mas sim ao contexto institucional em meio a qual esta decide, que obviamente con-

\section{REFERÊNCIAS}

ARANTES, Rogério Bastos. A crise do judiciário no Brasil. Trevisan, São Paulo, n. 104, 1996. . Judiciário e democracia no Brasil. Novos Estudos CEBRAP, São Paulo, n. 54, 1999.

. Judiciário e política no Brasil. São Paulo: Idesp, 1997.

ATIENZA, Manuel. As razões do argumento: teorias da argumentação jurídica. São Paulo: Landy, 2002.

AZEVEDO, Álvaro Villaça. Teoria geral dos contratos típicos e atípicos. São Paulo: Atlas, 2002.

BALBINOTTO NETO, Giácomo. Os reflexos das decisões judiciárias na economia. Palestra no Tribunal Regional Federal da $4^{\mathrm{a}}$ Região, 2004.

BERARDO, Telma. Soberania: um novo Conceito? Revista de Direito Constitucional e Internacional, São Paulo, n. 40, p. 26-29, jul./set. 2002.

BOBBIO, Norberto. Igualdade $e$ liberdade. São Paulo: Ediouro, 2000.

- Teoria dell'ordinamento giuridico. Torino: Giappichelli, 1960.

CASTRO, Marcus Faro de. O Supremo Tribunal Federal e a judicialização da política no Brasil. Revista Brasileira de Ciências Sociais, São Paulo, v. 12, n. 34, 1997. diciona o desempenho de todo Poder Judiciário. Se há alguma incerteza geradora de ineficiência econômica, esta parece se dever, quanto ao que neste texto se observou, mais a certas limitações estruturais do que a um eventual ativismo por parte dos julgadores.

COASE, Ronald. La empresa, el mercado y la ley. Madrid: Alianza, 1994. . The nature of the firm. Economica, 4, 1937.

COOTER, Robert; ULEN Thomas. Law and economics. [s.l.]: Addison Wesley Longman, 2000.

DAHRENDORF, Ralf. O conflito social moderno: um ensaio sobre a política da liberdade. Rio de Janeiro: Jorge Zahar; 1992,

FARIA, José Eduardo (Org.). Direito $e$ globalização econômica: implicações e perspectivas. São Paulo: MaIheiros, 1998.

FARIA, José Eduardo. Direito na economia globalizada. São Paulo: Malheiros, 2000.

FERRI, Giovanni B. La 'cultura' del contratto e le strutture del mercato. In: A L'EUROPE du troisième millénaire: mélanges offerts à Giuseppe Gandolfi : à l'occasion du dixième anniversaire de la fondation de l'Académie. [s.l.]: [s.n.], 2004. v. 1.

FIGUEIREDO, Argelina Cheibub; LIMONGI, Fernando. Executivo e legislativo na nova ordem constitucional. Rio de Janeiro: FGV, 1999.

GALGANO, Francesco. Diritto ed economia alle soglie del nuovo millennio. 
Contrato e Impresa, Padova, v. 17. n. $1,2000$.

. Las instituciones de la economía capitalista. Barcelona: Ariel, 1990.

- Lex mercatoria. Revista de Direito Mercantil, Industrial, Econômico e Financeiro, São Paulo, v. $129,2003$.

- La nuova lex mercatoria In: ATLANTE di diritto privato comparato. Bologna: Zanichelli, 1995.

GHERSI, Carlos Alberto. Contratos: problemática moderna. Mendoza: Cuyo, 1996.

GHESTIN, Jacques. Le contrat en tant qu'échange économique. Revue d'Economie Industrielle, n. 92, p. 81100, 2000, Numéro special, Économie des Contrats: Bilan et Perspective.

GOLDMAN, Berthold. Frontières du droit et lex mercatoria. Archives de Philosophie du Droit, n. 9, p: 177, 1964.

GOMES, Orlando; VARELA, Antunes. Direito económico. São Paulo: Saraiva, 1977.

GRAU, Eros Roberto. $O$ direito posto e $o$ direito pressuposto. São Paulo: Malheiros, 2002,

GUARNIERI, Carlo; PEDERZOLI; Patrizia. La puissance de juger: pouvoir judiciaire et démocratie. Paris: Michalon, 1996.

LOBO, Paulo Luiz Netto. Direito do estado federado ante a globalização econômica. Revista de Informação Legislativa, Brasília, v. 38, n. 151, p. 95-108, jul./set. 2001.

LORENZETTI, Ricardo. Tratado de los contratos. Buenos Aires: RubinzalCulzoni, 1999. v. 1
MACEDO JÚNIOR, Ronaldo Porto. Contratos relacionais no direito brasileiro. Disponível em: <http:// $136.142 .158 .105 /$ L A S A $97 /$ portomacedo.pdf>

Globalização e direito do consumidor. In: SUNFELD, Carlos Ari; VIEIRA, Oscar Vilhena. (Org.). Direito global. São Paulo: Max Limonad, 1999.

MARQUES, Cláudia Lima. Contratos no Código de Defesa do Consumidor: o novo regime das relações contratuais. São Paulo: Revista dos Tribunais, 2005.

MARTINS COSTA, Judith Hoffmeister. A reconstrução do direito privado: reflexos dos princípios, diretrizes e direitos fundamentais constitucionais no direito privado. São Paulo: Revista dos Tribunais, 2002.

MCGREW, Anthony. A global society? In: HALL, Stuart; HELD, David; MCGREW, Antony. Modernity and its futures. Cambridge: Polity, Open University, 1992.

MERQUIOR, José Guilherme. $O$ liberalismo: antigo e moderno. Rio de Janeiro: Nova Fronteira, 1991.

MONCADA, Luis Cabral de. Direito econômico. Coimbra: Coimbra, 1996.

NORTH, Douglass. Institutions: institutional change and economic performance. Cambridge: Cambridge University, 1990.

NUSDEO, Fábio. Fundamentos para uma codificação do direito econômico. São Paulo: Revista dos Tribunais, 1995.

OLIVEIRA, Vanessa Elias de. Judiciário e privatizações no Brasil: existe uma judicialização da política? Dados, Rio de Janeiro, v. 48, n. 3, 2005. 
PINHEIRO, Armando Castelar. Direito e economia num mundo globalizado: cooperação ou confronto? In: ANDRADE, Rogério E. de. (Org.). Regulação pública no Brasil. Campinas: Edicamp, 2003.

A reforma do judiciário: uma análise econômica. In: BRESSER PEREIRA, Luiz Carlos; WILHEIM, J.; SOLA, Lourdes (Org.). Sociedade e estado em transformação. São Paulo: UNESP, 2001.

A relação entre o desempenho das instituições jurídicas e o crescimento econômico. In: WALD, Arnold.; MARTINS, Ives Gandra S. e PRADO, N. (Org.). O direito brasileiro e os desafios da economia globalizada. São Paulo: América Jurídica, 2003.

PINHEIRO, Armando Castelar (Org.). Reforma do judiciário: problemas, desafios, perspectivas. Rio de Janeiro: Booklink, 2003.

PINHEIRO, Armando Castelar; CABRAL, Célia. Credit markets in brazil: the role of the judiciary and other institutions. In: PAGANO, M (Org.) Defusing default: incentives and institutions. [s.l.]: DB/OCDE, 2001.

POSNER, Richard. Economic analysis of law. Aspen, 2002.

REALE, Miguel. O estado democrático de direito e o conflito das ideologias. São Paulo: Saraiva, 1998.

REIS, Fábio Wanderley. Politica e racionalidade: problemas de teoria e método de uma sociologia crítica da política. Belo Horizonte: Ed. UFMG, 2000.

ROPPO, Enzo. O contrato. Coimbra: Almedina, 1988.

SANTOS, Fabiano. O poder legislativo no presidencialismo de coalizão. Belo Horizonte: Ed. UFMG, 2003.

SHAVELL, Steven M. Foundations of economic analysis of law. Harvard: Belknap, 2004.

STRENGER, Irineu. Direito internacional privado. 4. ed. São Paulo: LTr, 2000.

TILLY, Charles. Coerção, capital e estados europeus. São Paulo: Ed. USP, 1996.

TSEBELIS, George. Jogos ocultos: escolha racional no campo da política comparada. São Paulo: Ed.USP, 1998.

Veto players: how political institutions work. Princeton: Princeton University, 2002.

WALD, Arnoldo. A contratualização do direito societário. Direito Empresarial, Concorrencial e do Consumidor, n. 3, p. 50-54, jun./jul. 2005.

WEBER, Max. Ciência e politica: duas vocações. São Paulo: Cultrix, 2004.

WERNECK VIANNA, Luiz Jorge et al. A judicialização da política e das relações sociais no Brasil. Rio de Janeiro: Revan, 1999. 
